\title{
Effect of High-Pressure Torsion on the Microstructural Evolution and Mechanical Properties of an Fe-10Ni-7Mn (wt. \%) Lath Martensitic Steel
}

\author{
Faezeh Javadzadeh ${ }^{1, a)}$, Hamidreza Koohdar ${ }^{1, b)}$, Hamidreza Jafarian², c), \\ Mahmoud Nili-Ahmadabadi ${ }^{1,3, \text { d) }}$, Yi Haung ${ }^{4,}$,, Terence. G. Langdon ${ }^{4, \text { f) }}$ \\ ${ }^{1}$ School of Metallurgy and Materials Engineering, University of Tehran, P.O. Box 14395-731, Tehran, Iran \\ ${ }^{2}$ School of Metallurgy and Materials Engineering, Iran University of Science and Technology, Tehran, Iran \\ ${ }^{3}$ Center of Excellence for High Performance Materials, School of Metallurgy and Materials Engineering, University \\ of Tehran, Tehran, Iran \\ ${ }^{4}$ Materials Research Group, Faculty of Engineering and the Environment, University of Southampton, Southampton
} SO17 1BJ, UK

a) Corresponding author: fjavadzadeh@ut.ac.ir

b) h.koohdar@ut.ac.ir

c) jafarian@iust.ac.ir

d) nili@ut.ac.ir

e) y.huang@ @oton.ac.uk

f) langdon@soton.ac.uk

\begin{abstract}
The high-pressure torsion (HPT) process is a severe plastic deformation (SPD) technique which imposes exceptionally high strains to produce extremely small grain sizes in bulk materials. In this paper, the HPT process was carried out on an Fe-10Ni-7Mn (wt.\%) martensitic steel up to 20 revolutions at a rotation speed of $1 \mathrm{rpm}$ under a pressure of $6.0 \mathrm{GPa}$ at room temperature. The effects of the HPT process on the microstructure evolution and mechanical properties of the alloy were investigated by X-ray diffraction (XRD) analysis, electron backscatter diffraction (EBSD), microhardness measurement and conventional tensile testing. The XRD analysis revealed no changes in the detected phases after deformation. A significant refinement in grain size from $200 \mu \mathrm{m}$ in the initial microstructure to around $230 \mathrm{~nm}$ after HPT was observed by EBSD. Although based on a rigid body assumption the imposed strain is linearly proportional to the distance from the center in HPT-processed disks, after 20 revolutions a uniform micro-hardness increment up to $\sim 650 \mathrm{Hv}$ was achieved. Moreover, the tensile strength of the alloy increased from $\sim 800 \mathrm{MPa}$ in the solution annealed condition to about $2300 \mathrm{MPa}$ after the HPT process with a total tensile strain of 4\%. Experimental results indicated that the HPT process leads to improvement of the tensile strength with a reasonable ductility due to the significant refinement of the microstructure.
\end{abstract}

\section{INTRODUCTION}

Severe plastic deformation (SPD) techniques are defined as metal forming processes in which very large plastic strain are imposed on bulk metals in order to make ultrafine-grained (UFG) or nano-crystalline structures without any significant changes in the overall dimensions of the specimens [1,2]. Structures achieved during SPD have specific features such as high vacancy concentrations, low densities of free dislocations, high-angle misorientaion and high energy and non-equilibrium grain boundaries [3]. Therefore, severely deformed materials show unique and excellent properties such as high strength and low-temperature superplasticity compared with the conventional coarse-grained materials [4]. Various SPD methods such as equal-channel angular pressing (ECAP) [5], accumulative roll-bonding (ARB) [6], repetitive corrugation and straightening by rolling (RCSR) [7, 8], severe cold rolling [4, 9] and highpressure torsion (HPT) $[10,11]$ have been developed. Among these various SPD techniques, processing by highpressure torsion has attracted the most attention because of the capacity for achieving crack-free bulk materials with exceptional grain refinement, often to the nanometer level, and remarkably high strength [12, 13].

Fe-10Ni-7Mn (wt\%) lath martensitic steel shows excellent formability in the solution annealed state which makes it suitable for SPD processes [14]. This martensitic steel has good age hardenability but it suffers from embrittlement after aging. Discontinuous coarsening of grain boundary precipitates resulting in the formation of precipitate-free 
zones along prior austenitic grain boundaries was found as the main source of embrittlement in aged Fe-10Ni-7Mn steels [9]. The ductility improvement in this alloy has been the subject of many reports $[15,16]$. Grain refining has been known as an effective way to improve the strength and toughness of metallic materials [9]. In previous studies, the effect of various SPD methods such as cold rolling plus wire drawing [3, 16], cold rolling and ECAP [5], Severe Cold Rolling [15, 17], RCSR [7] and also the reverse transformation of martensite to austenite [17] on the microstructural evolution and mechanical properties of this alloy were investigated.

The present research is an attempt to study the effect of HPT processing on the microstructural evolution and mechanical properties of an Fe-10Ni-7Mn (wt.\%) alloy. The structural evolution was depicted by X-ray diffraction (XRD) analysis and electron backscatter diffraction (EBSD) analysis.

\section{EXPERIMENTAL PROCEDURES}

Fe-10Ni-7Mn (wt.\%) alloy was produced by vacuum induction melting (VIM) and vacuum arc remelting (VAR) routes. The remelted ingot was hot forged by $50 \%$ reduction at $1423 \mathrm{~K}$, homogenized in a vacuum furnace at $1473 \mathrm{~K}$ for 24 hours, then solution annealed at $1423 \mathrm{~K}$ for 1 hour and quenched in cold water to gain a fully martensitic microstructure. Disks with a diameter of $10 \mathrm{~mm}$ and a thickness of $0.8 \mathrm{~mm}$ were subjected to HPT processing under an applied pressure of $6 \mathrm{GPa}$ and a rotation rate of $1 \mathrm{rpm}$ for 20 revolutions at room temperature. Microstructures were characterized by X-ray diffraction (XRD) analysis using $\mathrm{Cu}-\mathrm{K} \alpha$ radiation with angular ranges of $45-100^{\circ} 2 \theta$ and a step scanning rate of $0.02^{\circ}$ per $3.6 \mathrm{~s}$ and electron backscatter diffraction (EBSD). Miniature tensile specimens of 0.8 $\mathrm{mm}$ width and $0.4 \mathrm{~mm}$ thickness with gauge length of $1.8 \mathrm{~mm}$ were wire cut at a distance of $2.5 \mathrm{~mm}$ from the center of the HPT samples. Tensile testing was performed using a SANTAM tensile testing machine with an initial strain rate of $5 \times 10^{-4} \mathrm{~s}^{-1}$. For micro-hardness measurements, each processed disk was mounted and polished to have a mirrorlike surface and measurements were taken at positions separated by $1 \mathrm{~mm}$ across the diameters of each disk using the Vickers method at a load of $100 \mathrm{gf}$ and $10 \mathrm{~s}$ dwell time.

\section{RESULTS AND DISCUSSION}

Fig. 1, shows the XRD pattern of the sample before and after HPT process. X-ray analysis demonstrates that after HPT (curve b) no austenite peak is detected and the specimen is almost entirely composed of the martensite phase as in a solution annealed sample (curve a). The first XRD peak in solution annealed and HPT-processed samples is also shown in Fig. 1. The observed peak broadening after the HPT process is attributed to the effect of severe plastic deformation in developing grain refinement and shear strain.

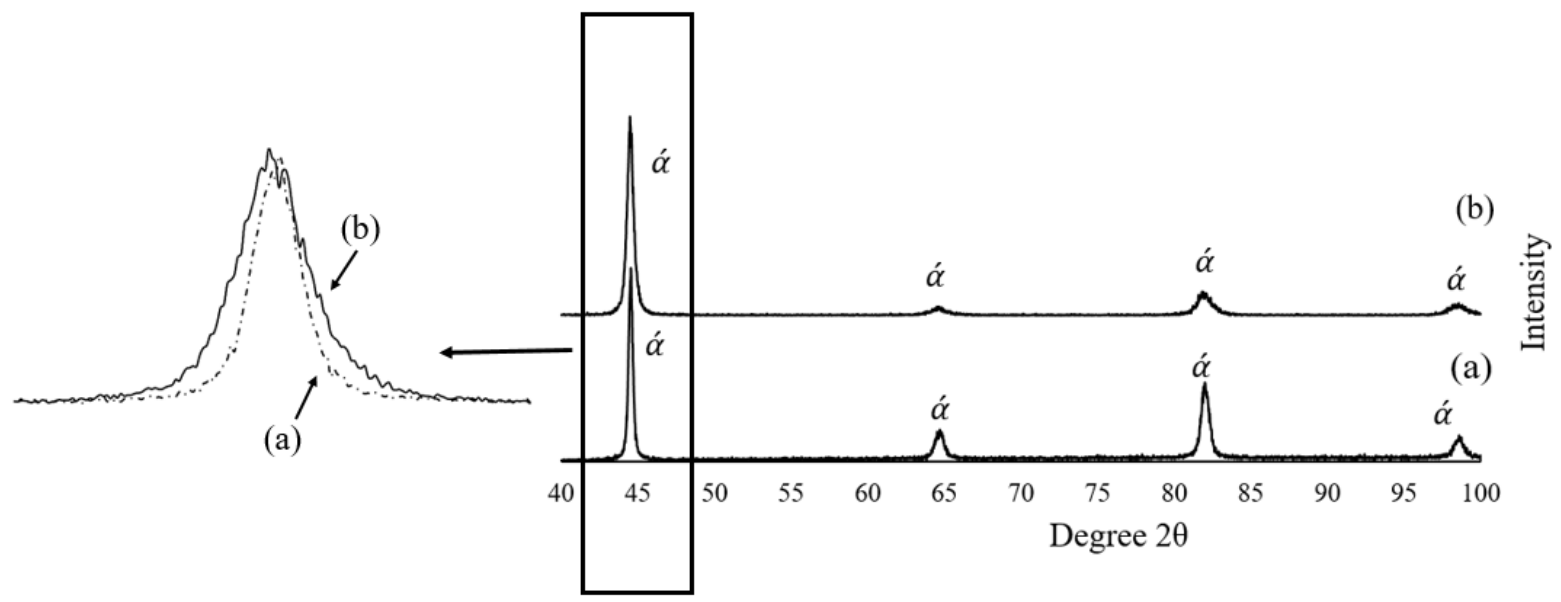

FIGURE 1. The X-ray diffraction pattern for samples solution annealed (curve a) and HPT-processed (curve b).

Grain boundary maps together with phase maps of the solution annealed and HPT-processed specimens are shown in Fig. 2a and b, respectively. According to Fig. 2b, the average grain size after deformation is about $230 \mathrm{~nm}$ and this shows a significant refinement by comparison with the solution annealed specimen with an initial grain size of about $200 \mu \mathrm{m}$ (Fig. 2a). The microstructure in Fig. 2b consists of both equiaxed and elongated grains along the shear 
direction accompanied by some nucleations of an austenitic phase at grain boundaries. Due to the low volume fraction $(\sim 4 \%)$ and small grain size of the deformation-induced austenite, the peak of austenite is invisible in the XRD pattern of the HPT-processed specimen (Fig. 1b). The observation of even small quantities of austenite in severely deformed Fe-Ni-Mn martensitic steel, which by definition contained no austenite prior to the deformation, indicates that the reverse transformation of martensite to austenite occurred under deformation at room temperature. During deformation at room temperature, austenite can form from bcc-martensite by a displacive mechanism with an orientation relationship between austenite and bcc-martensite grains that are based on the Kurdjumov-Sachs (K-S) relationship [15]. At first, bcc-martensite transforms to hcp-martensite then hcp-martensite transforms to austenite after further straining. This austenite can cause a major improvement in the mechanical properties after aging [9]. Furthermore, it has been reported that reversion transformation together with plastic deformation during HPT can play a crucial role in grain refinement. As a result, the grain refinement phenomenon combined with plastic deformation would saturate more efficiently compared to grain refinement induced only by the HPT process. Hence, it is expected that a combination of reverse transformation and the HPT process accelerates grain refinement and the formation of ultrafine grains [18].

The values of the Vickers micro-hardness recorded across the diameter of each disk are plotted against the distance from the center in Fig. 3, where each point is an average of the five values measured at the same distance from the center. It is apparent that when the disk is strained up to 20 revolutions the micro-hardness increases to a higher level and a saturation hardness value is obtained which extends at $\sim 1 \mathrm{~mm}$ from the center to the outer region of the disk. The increment in hardness is attributed to the distorted microstructure, high dislocation density and refined grains.

Fig. 4 shows the engineering stress-strain curves of the alloy in the solution annealed and HPT-processed conditions. The solution-annealed specimen shows moderate tensile strength $(\sim 830 \mathrm{MPa})$ and ductility $(\sim 11 \%)$. However, HPT increases the tensile strength to about $2300 \mathrm{MPa}$ with a marginal ductility loss to about $4 \%$. This process results in a $175 \%$ increase in tensile strength and the ductility is decreased by about $60 \%$.

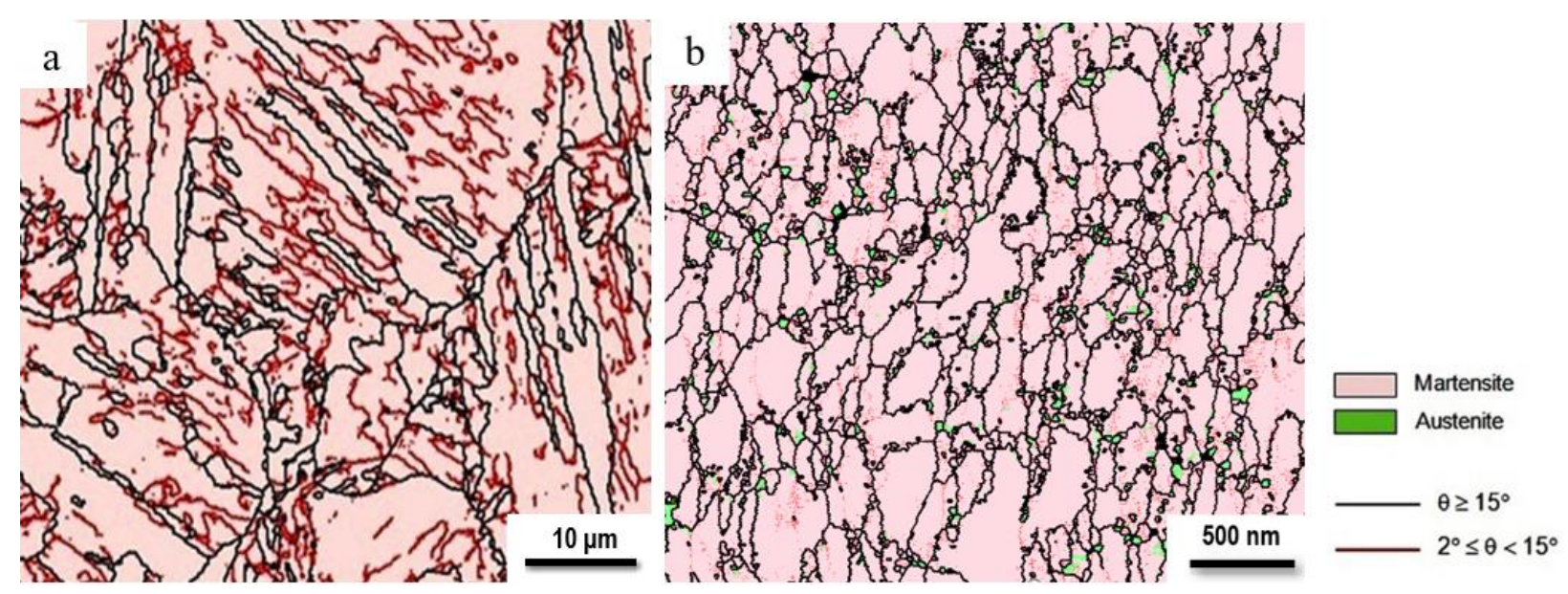

FIGURE 2. EBSD Phase maps for samples (a) solution annealed and (b) HPT-processed. 


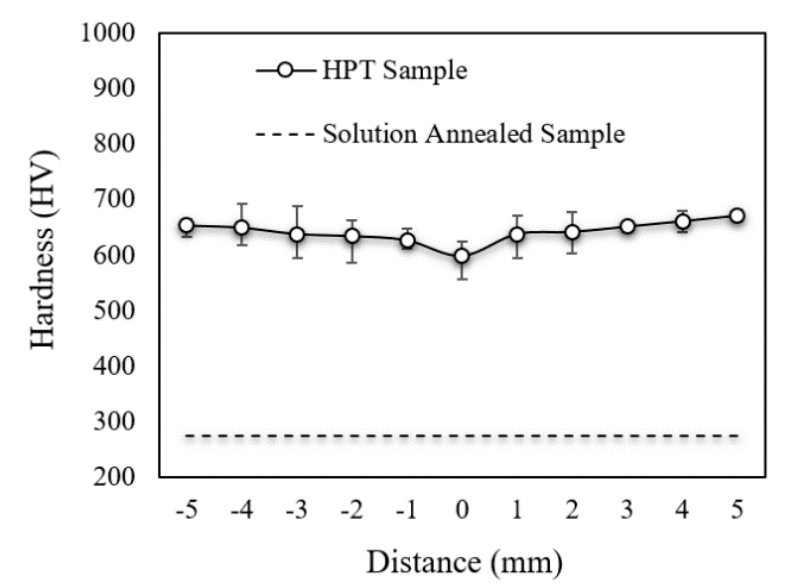

FIGURE 3. Variation in the average Vickers micro-hardness recorded across the diameter of the solution annealed and HPTprocessed samples.

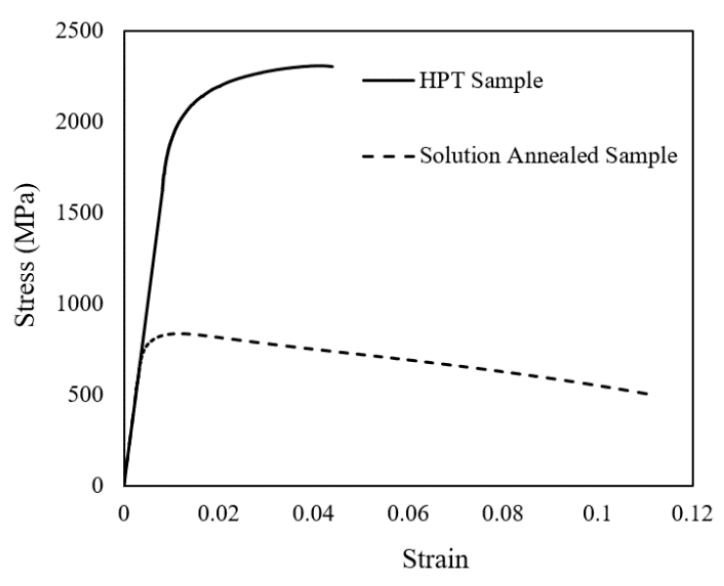

FIGURE 4. Engineering stress-strain curve of solution annealed and HPT-processed samples.

In order to compare the HPT processing with other severe plastic deformation methods, tensile property results of previous and present studies are shown in Table 1. It should be noted that the difference in gauge dimensions in these studies may have some impact on the measured elongations. It is found that severe cold rolling $(\varepsilon \approx 2.18)$ improves the tensile properties of the steel. It is believed that ae specific combination of the elongated and equiaxed grains provided the desired ductility in the longitudinal direction of the rolled strip [5]. In ECAP steel $(\varepsilon \approx 4)$, the microstructure is more eqiuaxed and coarse precipitates may be formed at grain boundaries. Such a structure is found to represent high tensile strength but low tensile ductility [19]. In attempting to achieve a better understanding of the improved toughening via cold rolling and wire drawing over the equal-channel angular pressing, the presence of austenite particles also should be taken into account. Austenite is known as a ductile crack-arresting phase in maraging steels which often improves the ductility at the expense of yield strength. Severe plastic deformation accumulates a high density of dislocations, increasing the Gibbs free energy of the deformed structure which favors austenite stabilization. Therefore, the reverse transformation of martensite into austenite seems likely to occur during cold rolling and wire drawing of the present steel to be manifested either by a displacive mechanism as reported for a plain carbon steel or as a diffusional process if adiabatic heating augments solute diffusion during deformation [19].

Table 1. Tensile properties of the solution annealed and various SPD processed $\mathrm{Fe}-10 \mathrm{Ni}-7 \mathrm{Mn}$ samples

\begin{tabular}{cccccc}
\hline Sample & $\begin{array}{c}\text { Yield Strength } \\
(\mathbf{M P a})\end{array}$ & $\begin{array}{c}\text { Ultimate Tensile } \\
\text { Strength }(\mathbf{M P a})\end{array}$ & Total Strain $(\%)$ & $\begin{array}{c}\text { Gauge } \\
\text { Dimensions(mm) }\end{array}$ & Reference \\
\hline As annealed & 820 & 835 & 11.1 & $0.4 \times 0.8 \times 1.8$ & present \\
As annealed & 650 & 880 & 17 & $2 \times 2.5 \times 9.8$ & {$[5]$} \\
HPT & 2030 & 2300 & 4.4 & $0.4 \times 0.8 \times 1.8$ & present \\
85\% Cold rolling & 820 & 950 & 14 & $2 \times 2.5 \times 9.8$ & {$[5]$} \\
ECAP & 1000 & 1100 & 12 & $2 \times 2.5 \times 9.8$ & {$[5]$} \\
Cold rolling \& & - & 1740 & 7 & $2 \times 2.5 \times 9.8$ & {$[19]$} \\
wire drawing & - & 910 & 8.6 & $2 \times 2.5 \times 9.8$ & {$[7]$} \\
RCSR & - & & & & \\
\hline
\end{tabular}

As noted, the mechanical tests on HPT-processed sample $(\varepsilon>\sim 100)$ gave an increase in tensile strength and a sharp decrease in ductility. Higher strength after HPT is attributed to the effect of severe plastic deformation, which causes a high density of dislocations leading toa high density of shear bands and very fine grains. The ductility reduction may be a result of dislocation generation and accumulation in the shear bands, grain boundaries and the enhancement of strain hardening in the micro-voids during the deformation process. These micro-voids are generated due to the excess free volume in HPT materials in the accumulated high energy points of the microstructure. The nonequilibrium grain boundaries in the severely deformed polycrystals are assumed to contain a higher excess free volume or non-equilibrium vacancies [20]. The concentration of deformation-induced vacancies increases with increasing 
strain which leads to the formation of larger vacancy clusters and even submicron cracks. These defects may affect the fracture behavior during tensile deformation.

\section{CONCLUSIONS}

Effect of severe plastic deformation by means of high-pressure torsion on the microstructure and mechanical properties of an $\mathrm{Fe}-10 \mathrm{Ni}-7 \mathrm{Mn}$ (wt.\%) martensitic steel was studied. The main conclusionsare as follows:

1. Fe-10Ni-7Mn (wt. \%) processed by HPT at room temperature achieves a significant grain refinement and strength enhancement. The grain size is reduced from an initial value of $\sim 200 \mu \mathrm{m}$ to $\sim 230 \mathrm{~nm}$ and the hardness increases from 275 to $\sim 650 \mathrm{Hv}$ after 20 turns of HPT.

2. EBSD results show about $4 \%$ austenite phase in martensite grain boundaries after HPT processing which indicates a reverse transformation of martensite to austenite during HPT processing at room temperature.

3. Results from tensile tests show that the HPT-processed alloy has high ultimate tensile strength about 2300 MPa and ductility of $\sim 4 \%$. The results demonstrate that, even when considering the reduced gauge lengths in HPT tensile specimens, the HPT-processed alloy has superior mechanical properties byn comparison with samples processed by ECAP, severe cold rolling or RCSR.

4. The grain refinement and austenite formation achieved by HPT processing may lead to an improvement in ductility and toughness after aging.

\section{REFERENCES}

[1] A. Azushima, R. Kopp, A. Korhonen, D.Y. Yang, F. Micari, G.D. Lahoti, P. Groche, J. Yanagimoto, N. Tsuji, A. Rosochowski, A. Yanagida, "Severe plastic deformation (SPD) processes for metals," CIRP Annals Manufacturing Technology, vol. 57, pp. 716-735, 2008.

[2] K. Hans Raj, Rahul Swarup Sharma, Pritam Singh, Atul Dayal, "Study of friction stir processing (FSP) and high pressure torsion (HPT) and their effect on mechanical properties," Procedia Engineering, vol. 10, pp. 29042910, 2011.

[3] H. Ghasemi-Nanesa, M. Nili-Ahmadabadi, H. Shirazi, "Mechanical properties of Fe -10Ni -7Mn martensitic steel subjected to severe plastic deformation via cold rolling and wire drawing," Journal of Physics, 2010.

[4] H. Ghasemi-Nanesa, M. Nili-Ahmadabadi, H.R. Koohdar, M. Habibi-Parsa,S. Hossein Nedjad, S.A. Alidokhte and Terence G. Langdon, "Strain-induced martensite to austenite reverse transformation in an ultrafine-grained Fe-Ni-Mn martensitic steel," Philosophical Magazine, vol. 94, p. 1493-1507, 2014.

[5] H. Shirazia, M. Nili-Ahmadabadi, A. Fatehia and S. Hossein Nedjad, "Effect of Severe Plastic Deformation on Mechanical Properties of Fe-Ni-Mn High Strength Steel," Advanced Materials Research, Vols. 83-86, pp. 1623, 2010.

[6] S. Tirekar, H.R. Jafarian, A.R. Eivani, "Towards engineering of mechanical properties through stabilization of austenite in ultrafine grained martensite-austenite dual phase steel processed by accumulative roll bonding," Materials Science \& Engineering A, vol. 684, pp. 120-126, 2017.

[7] Arya Mirsepasi, Mahmoud Nili-Ahmadabadi, Mohammad Habibi-Parsa, Hadi Ghasemi-Nanesa, Ahmad F. Dizaji, "Microstructure and mechanical behavior of martensitic steel severely deformed by the novel technique of repetitive corrugation and straightening by rolling," Materials Science and Engineering A, vol. 551, pp. 3239, 2012.

[8] Peyman Asghari-Rad, Mahmoud Nili-Ahmadabadi, Hassan Shirazi, Syamak Hossein Nedjad and Sebastian Koldorf, "A Significant Improvement in the Mechanical Properties of AISI 304 Stainless Steel by a Combined RCSR and Annealing Process," Advanced Engineering Materials, 2016. 
[9] H. Ghasemi- Nanesa, M. Nili Ahmadabadi, H. Shirazi, S. Hossein Nejad, "Observation of Reverse Transformation of $\alpha-\varepsilon-\gamma$ in ultrafine - grained Fe-Ni-Mn Age Hardenable Martensitic Steel," International Journal of Modern Physics, vol. 5, pp. 9-17, 2012.

[10] Kaveh Edalati, Zenji Horita, "A review on high-pressure torsion (HPT) from 1935 to 1988," Materials Science \& Engineering A, vol. 652, pp. 325-352, 2016.

[11] Yoshikazu Todaka, Yoshii Miki, Minoru Umemoto, Chaohui Wang and Koichi Tsuchiya, "Tensile Property of Submicrocrystalline Pure Fe Produced by HPT-straining," Materials Science Forum, Vols. 584-585, pp. 597602, 2008.

[12] A. Vorhauer, R. Pippan, "On the homogeneity of deformation by high pressure torsion," Scripta Materialia, vol. 51, pp. 921-925, 2004.

[13] Diana Maritza Marulanda Cardona, Jittraporn Wongsa-Ngam, Terence G. Langdon, "Microstructural evolution and microhardness in a low carbon steel processed by high-pressure torsion," $\mathrm{j}$ mater res technol, pp. 344-348, 2014.

[14] Hadi Ghasemi-Nanesa, Mahmoud Nili-Ahmadabadi, Arya Mirsepasi, and Cyrus Zamani, "Nano- and Microvoid Formation in Ultrafine-Grained Martensitic Fe-Ni-Mn Steel After Severe Cold Rolling," Met. Mater. Int., Vols. 201-205, p. 20, 2014.

[15] Hamidreza Koohdar, Mahmoud Nili-Ahmadabadi, Mohammad Habibi-Parsa, Hadi Ghasemi-Nanesa, "Investigating on the reverse transformation of martensite to austenite and Pseudoelastic behavior in UltrafineGrained Fe-10Ni-7Mn (wt \%) Steel processed by heavy cold rolling," Advanced Materials Research, vol. 829, pp. 25-29, 2014.

[16] H. Ghasemi-Nanesa, M. Nili-Ahmadabadi, H. Shirazi, S. Hossein Nedjad, S.H. Pishbin, "Ductility enhancement in ultrafine-grained $\mathrm{Fe}-\mathrm{Ni}-\mathrm{Mn}$ martensitic steel by stress-induced reverse transformation," Materials Science and Engineering A, vol. 527, p. 7552-7556, 2010.

[17] H.R. Koohdar, M. Nili-Ahmadabadi, M. Habibi-Parsa, H.R. Jafarian, H. Ghasemi-Nanesa, H. Shirazi, "Observation of pseudoelasticity in a cold rolled Fe-Ni-Mn martensitic steel," Materials Science \& Engineering A, vol. 658, pp. 86-90, 2016.

[18] H.R. Jafarian, Mohammad Falaki Tarazkouhi, "Significant enhancement of tensile properties through combination of severe plastic deformation and reverse transformation in an ultrafine/nano grain lath martensitic steel," Materials Science \& Engineering A, vol. 686, pp. 113-120, 2017.

[19] M. Nili Ahmadabadi, H. Shirazi, H. Ghasemi-Nanesa, S. Hossein Nedjad, B. Poorganji, T. Furuhara, "Role of severe plastic deformation on the formation of nanograins and nano-sized precipitates in $\mathrm{Fe}-\mathrm{Ni}-\mathrm{Mn}$ steel," Materials and Design, vol. 32, pp. 3526-3531, 2011.

[20] Y.Z. Tian, J.J. Li, P. Zhang, S.D. Wu, Z.F. Zhang, M. Kawasaki, T.G. Langdon, "Microstructures, strengthening mechanisms and fracture behavior of $\mathrm{Cu}-\mathrm{Ag}$ alloys processed by high-pressure torsion," Acta Materialia, vol. 60, pp. 269-281, 2012. 